REMOA (Revista Eletrônica do Curso de Especialização em Educação Ambiental da UFSM)

\title{
PROJETO RONDON: ATIVIDADES DESENVOLVIDAS NA OPERAÇÃO MAMORÉ, NO MUNICÍPIO DO VALE DO ANARI, RO, 2010.
}

\author{
Lauren Oliveira Lima Bohner ${ }^{1}$, Luiz Jarbas Godoy Filho ${ }^{1}$, Graziela de Luca Canto ${ }^{2}$ \\ ${ }^{1}$ Acadêmico(a) do Curso de Odontologia (UFSC). \\ laurenamp@hotmail.com \\ ${ }^{2}$ Professora e Coordenadora do curso de graduação em Odontologia (UFSC) \\ delucacanto@gmail.com
}

\section{RESUMO}

O presente estudo tem como objetivo relatar a experiência das atividades de extensão desenvolvidas durante a Operação Mamoré, ocorrida em julho de 2010, em Vale do Anari, Rondônia. Durante duas semanas, oito acadêmicos da Universidade Federal de Santa Catarina, acompanhados de dois professores, promoveram ações que beneficiassem a região. Com as crianças e adolescentes, foram realizadas atividades de lazer e promoção de saúde. Para a população adulta, nas áreas de Tecnologia e Meio Ambiente, foram desenvolvidos cursos de informática, realização de projetos e análise de água, durante três dias cada, e com certificado reconhecido pela Universidade Federal de Santa Catarina. Para os idosos, desenvolveram-se Oficinas de Artesanato, palestras sobre alimentação saudável e Oficinas sobre câncer Bucal, pressão Arterial, diabetes e higienização de Próteses Dentária. O município Vale do Anari possui problemas de relevância social, como deficiência no sistema de saúde, educação e utilização de recursos ambientais e tecnológicos. A Operação Mamoré procurou realizar ações que contribuíssem para o desenvolvimento sustentável da comunidade, entretanto, é necessária a criação de projetos contínuos que beneficiem a população para o crescimento do município e melhoria da qualidade de vida da população. As ações realizadas durante o Projeto Rondon contribuíram não só para o desenvolvimento do município, mas também para fortalecer o conceito de cidadania entre os rondonistas.

Palavras-chave: Rondon, desenvolvimento sustentável, saúde, cidadania.

\section{ABSTRACT}

The present study aims to report the extension activities experience developed during Mamore Operation, on July 2010, at Vale do Anari, Rondônia. For two weeks, eight students from Federal University of Santa Catarina, instructed by two teachers, promoted benefit actions in the region. With children and adolescents, it was performed leisure and health promotion activities. Concerning the adult population, it was developed activities on the technology and environment 


\section{Monografias Ambientais}

REMOA (Revista Eletrônica do Curso de Especialização em Educação Ambiental da UFSM)

areas, such as computer courses, completion of projects and water analysis, with recognized certificate from the Federal University of Santa Catarina. For the elderly, it was developed handicrafts workshops, healthy eating lectures and oral cancer, blood pressure, diabetes and cleaning of dental prostheses workshops. Vale do Anari city has socially relevant issues, as deficiency in health care, education and use of environmental resources and technology. Operation Mamoré tried to perform actions that contributed to sustainable community development. However, it requires the creation of ongoing projects that benefits the population in order to the city development and quality of life improvement. The actions taken during the Rondon Project not only contributed to the city development, but also to strengthen the citizenship concept among the rondonistas.

Keywords: Rondon, sustainable development, health, citizenship

\section{INTRODUÇÃO}

A Universidade é um local onde a aquisição de conhecimentos permite a formação de conceitos, construção de autonomia e formação dos alunos como cidadãos conscientes. Uma educação de qualidade deve permitir a intervenção do educando nos desafios da sociedade, através da ampliação da aprendizagem desenvolvida por projetos de pesquisa e extensão (CASTILHO \& CASTILHO, 2011). A realização de Projetos de Extensão dentro do campo universitário integra a promoção da interdisciplinariedade, a democratização do conhecimento acadêmico e a formação de uma visão integrada do social. Além disso, permite que haja uma relação entre a Universidade e a Comunidade, através da articulação do ensino e da pesquisa (SARAIVA, 2007).

O projeto é realizado de acordo com o conhecimento acadêmico no âmbito da comunidade, e o aprendizado vivenciado pelo estudante, por sua vez, será acrescido ao conhecimento teórico, beneficiando assim, não só quem recebe a ação, mas também quem a realiza (SARAIVA, 2007). A participação do estudante universitário no desenvolvimento de projetos sociais contribui para a formação de profissionais aptos a lidar com os desafios da sociedade, além de estimular o crescimento pessoal e a capacidade de autocrítica (SBERGA, 2011).

O Projeto Rondon é um Projeto de Extensão coordenado pelo Ministério da Defesa, onde estudantes universitários participam voluntariamente na busca de soluções que contribuam para o desenvolvimento sustentável de comunidades carentes, ampliando o bem-estar da população (Projeto Rondon, 2011). Nesse sentido, busca-se realizar medidas que promovam a saúde da comunidade, através da criação de políticas saudáveis, fortalecimento da ação comunitária e capacitação de agentes multiplicadores em áreas que promovam a melhoria na qualidade de vida da população.

Além da assistência às comunidades, a ação tem como objetivo incorporar o estudante universitário nas desigualdades sociais, construindo um papel de cidadania no acadêmico, e, consequentemente, resultando em uma formação compromissada com as necessidades brasileiras(SARAIVA, 2007). Segundo Castilho \& Castilho (2007), o projeto promove a socialização 


\section{Monografias Ambientais}

REMOA (Revista Eletrônica do Curso de Especialização em Educação Ambiental da UFSM)

de experiências locais e regionais, incentivando a criação de ações inovadoras em benefício das comunidades necessitadas do País.

O Projeto Rondon surgiu em 1967 e permaneceu ativo até o final da década de 80, quando deixou de receber prioridade no governo federal, sendo então extinto. No ano de 2005 foi restabelecido, retornando à sua atividade, e até hoje vem se consolidando e atraindo estudantes de diferentes partes do país, que o utilizam como uma ferramenta de transformação social. A atuação dos Rondonistas ocorre nas áreas com maior índice de pobreza e exclusão social e, por isso, prioriza as regiões norte e nordeste do país (Projeto Rondon, 2011).

No período de julho de 2010, a Universidade Federal de Santa Catarina (UFSC) participou da Operação Mamoré, em Vale do Anari, Rondônia. O município, localizado no leste do Estado, possui uma população de 7.737 habitantes e IDH de 0,688 . Apresenta carência especialmente na atenção básica à saúde, área pedagógica e na utilização de recursos ambientais e tecnológicos. A ação teve como objetivo a capacitação de agentes multiplicadores em diversas áreas da educação, saúde, meio ambiente, lazer e cultura, além da difusão de conhecimento sobre temas relevantes à comunidade.

O presente estudo tem como objetivo relatar a experiência das atividades de extensão desenvolvidas durante a Operação Mamoré, ocorrida em julho de 2010, em Vale do Anari, Rondônia.

\section{MATERIAIS E MÉTODOS}

O Projeto foi realizado em Julho de 2010, em Vale do Anari, Rondônia. Durante duas semanas, oito acadêmicos da Universidade Federal de Santa Catarina, acompanhados de dois professores, promoveram ações que beneficiassem a região. Primeiramente, realizou-se o reconhecimento do ambiente, com o objetivo de diagnosticar as principais carências da população. A seguir, foram desenvolvidos projetos que abrangiam a população nas diferentes faixas etárias: crianças, adolescentes, adultos e idosos. Todos os projetos e aulas foram desenvolvidos e ministrados pelos estudantes universitários, com a supervisão dos professores. Para a divulgação e realização das atividades foram utilizados panfletos, rádio, projetor de slides, estufa microbiológica, computadores e materiais odontológicos.

Com as crianças e adolescentes, foram realizadas atividades de lazer e promoção de saúde. Dentre as atividades de lazer, estão as oficinas de artesanato, para aprendizagem de confecção de instrumentais, Gincana do Meio Ambiente, destacando a importância da reciclagem, Oficina de Desenho, permitindo às crianças explorar sua criatividade, e Tarde de Jogos e Lazer, onde realizouse competição de jogos e brincadeiras. Na área de educação e promoção de saúde, foi realizada uma palestra sobre Educação sexual para meninas, onde assuntos relacionados ao sexo e crescimento corporal foram discutidos. Em relação à saúde bucal, foi ministrada uma palestra sobre Higiene Bucal, distribuição de escovas de dente, e, juntamente com a Universidade São José, do Rio de Janeiro, realizou-se a Tarde da Saúde, envolvendo atividades de escovação supervisionada, aplicação de flúor e procedimentos de ART. 


\section{Monografias Ambientais}

REMOA (Revista Eletrônica do Curso de Especialização em Educação Ambiental da UFSM)

Para a população adulta, nas áreas de Tecnologia e Meio Ambiente, foram desenvolvidos cursos de informática, realização de projetos e análise de água, durante três dias cada, e com certificado reconhecido pela Universidade Federal de Santa Catarina. Na área de saúde bucal, os alunos de Odontologia ministraram aulas em um Curso de Formação de Auxiliar de Consultório Odontológico, oferecido pela Universidade de São José. A capacitação foi realizada em um período de 400 horas, entre aulas teóricas e práticas, com certificado emitido pela Universidade São José e reconhecido pelo MEC. Incentivando o Ensino Pedagógico, foi realizado um Mutirão da Educação, onde os universitários discutiam com os adultos que possuíam o segundo grau incompleto, para incentivar o retorno aos estudos. Na área cultural, foi realizada uma Feira de Produtos Artesanais, a fim de incentivar o comércio local. Para o lazer, durante uma semana realizou-se o Projeto Cine Night, onde um telão instalado na Praça Pública reuniu a população para assistir a filmes de comédia e ação.

Para os idosos, desenvolveu-se Oficinas de Artesanato, palestras sobre alimentação saudável e Oficinas sobre câncer Bucal, pressão Arterial, diabetes e higienização de Próteses Dentária.

\section{RESULTADOS E DISCUSSÃO}

A população de forma geral participou ativamente das atividades desenvolvidas pelos Rondonistas, de forma que o interesse da população foi demonstrado durante a execução das mesmas. Destaca-se a grande quantidade de pessoas presentes nas oficinas, feiras e atividades recreativas realizadas.

As crianças se mostraram muito estimuladas em participar das atividades de lazer. A palestra de educação sexual contou com a participação de 12 crianças do sexo feminino, onde foram levantadas questões sobre corpo, sexo, doenças sexualmente transmissíveis, menstruação e uso da pílula anticoncepcional. Dentre os temas relacionados ao sexo, destaca-se a discussão sobre abuso sexual, considerado um problema comum da população rondoniense. A palestra sobre saúde bucal e a Tarde da Saúde contaram com um número grande de crianças, e foi percebido uma deficiência na saúde bucal da população.

Todas as oficinas realizadas tendo como público-alvo os adultos atingiram um número elevado de inscritos. Os alunos mostraram bastante interesse nos temas estudados, e se mostraram incentivados a utilizar posteriormente o que lhes foi ensinado. $O$ curso de Auxiliar de Consultório Odontológico atingiu o número máximo de vagas, e todos os alunos foram aprovados nas avaliações teóricas e práticas. No Mutirão da Educação, um total de quarenta adultos mostraram interesse em realizar a matrícula no próximo ano letivo. A Feira de Artesanato procurou incentivar o comércio local de produtos artesanais, assim como a formação de Cooperativas locais. O Projeto Cine Night contou com a participação da população em geral. Além de promover a socialização entre a comunidade, incentivou o comércio de produtos alimentícios durante a apresentação do filme. O Projeto teve continuação após o término do Projeto Rondon, sendo realizado todas as sextas-feiras.

As oficinas e palestras em geral voltadas para os idosos foram realizadas durante a reunião do gupo dos idosos, contando com a participação de um grande número de idosos. Este público- 
REMOA (Revista Eletrônica do Curso de Especialização em Educação Ambiental da UFSM)

alvo é bem assistido no Município, que conta com atividades específicas que buscam proporcionar uma melhor qualidade de vida para o grupo.

\section{CONCLUSÃO}

As ações realizadas durante o Projeto Rondon contribuíram não só para o desenvolvimento do município, mas também para fortalecer o conceito de cidadania entre os rondonistas.

O município Vale do Anari possui problemas de relevância social, como deficiência no sistema de saúde, educação e utilização de recursos ambientais e tecnológicos. A Operação Mamoré procurou realizar ações que contribuíssem para o desenvolvimento sustentável da comunidade, entretanto, é necessária a criação de projetos contínuos que beneficiem a população para o crescimento do município e melhoria da qualidade de vida da população.

\section{REFERÊNCIAS}

BARRETO, A.S." Um lugar chamado Brejão: A atuação da equipe UFU no Projeto Rondon 2007”. Em Extensão, v. 6, 2007.

BRASIL. Ministério da Defesa. Projeto Rondon. Disponível em http://projetorondon.paginaoficial.com/portal/index/pagina/id/343/area/ C/module/default. Acesso em: 20 maio. 2011.

BULHÕES, A.E.E.; RAMOS, E.S.; FEIJÓ, E.V.R.S.; SANTOS, L.P.S. "Relato de uma experiência de vida: Comunidade e rondonistas integrando saberes". Extensio: R. Eletr. de Extensão, n. 10, p. 158-172, 2010.

CASTILHO, M.L.R.; CASTILHO, A.L. "A Universidade e os Projetos Sociais: Projeto Rondon - Cooperação entre a universidade e comunidades do Estado do Mato Grosso/ MT". Disponível em http://www.estudosdotrabalho.org/anais6seminariodotrabalho/myrianluciaruizcastilhoeandreluizcastilho.pdf. Acesso em: 30 maio. 2011.

DE SOUZA, O.S.S. “A extensão universitária e as universidades populares”. Revista da Faced, no 09, 2005253.

PEREIRA, L.R.P.; TEODORO, F.A.; PAULA, E.F.; CHAVES, V. "Metodologia aplicada à promoção de saúde bucal durante o Projeto Rondon: Operação Vale do Ribeira 2006". DENS, v.14(2), 2006.

SANTOS, M. S. S.; MENDES, I. A. C. "Projeto Rondon: a metodologia educativo-assistencial de trabalho dos estagiários universitários". Esc. Anna Nery R Enf, v.9(1), p.124-137, 2005.

SARAIVA, J.L. "Papel da Extensão Universitária na formação de estudantes e professores". Brasília Med ; 44(3): 220-225, 2007.

VIEIRA, M.R.M.; VIEIRA, M.M. "Atuação do Projeto Rondon em Comunidade Quilombola do norte de Minas Gerais - Um relato de experiência". Revista Afrounimontes, v. 01(01), 2011. 